\title{
$K R A S$ and $N R A S$ mutation detection in circulating DNA from patients with metastatic colorectal cancer using BEAMing assay: Concordance with standard biopsy and clinical evaluation
}

\author{
ELENA LASTRAIOLI ${ }^{1}$, LORENZO ANTONUZZO $^{2}$, BEATRICE FANTECHI $^{2}$, LUISA DI CERBO ${ }^{2}$, \\ ALESSANDRO DI COSTANZO $^{2}$, DANIELE LAVACCHI ${ }^{2}$, MIRIAM ARMENIO $^{1}$, ANNAROSA ARCANGELI ${ }^{1}$, \\ FRANCESCA CASTIGLIONE $^{3}$, LUCA MESSERINI ${ }^{1}$ and FRANCESCO DI COSTANZO ${ }^{2}$
${ }^{1}$ Department of Experimental and Clinical Medicine, University of Florence, I-50134 Florence; ${ }^{2}$ Medical Oncology Unit, Azienda Ospedaliero-Universitaria Careggi; ${ }^{3}$ Section of Pathological Anatomy, Department of Health Sciences, University of Florence, Azienda Ospedaliero-Universitaria Careggi, I-50134 Florence, Italy

Received January 31, 2020; Accepted August 24, 2020

DOI: $10.3892 / 01.2020 .12276$

\begin{abstract}
Patients with metastatic colorectal cancer (mCRC) are routinely screened for either $K$ - and $N-R A S$ to select the appropriate treatment. The present study aimed to evaluate the concordance between $K$ - and NRAS status in the tissue (either primary tumor or metastasis) and the plasma of patients with mCRC and to identify the associations between $K$ - and NRAS mutations in ctDNA and the clinicopathological parameters. Samples from a total of 31 patients with mCRC with measurable disease according to the Response Evaluation Criteria in Solid Tumors were analyzed. For all patients, $K$ - and NRAS status was determined in the tissue by matrix-assisted laser desorption/ionization time of flight mass spectrometry. For the detection of $R A S$ mutations in cell-free tumor DNA also defined as circulating tumor DNA (ctDNA), the OncoBEAM ${ }^{\circledR}$ RAS CRC kit (Sysmex Inostics) was used. A total of 6/31 tissue samples expressed wild-type $K R A S$, whereas $25 / 31$ presented mutations. In addition, 7/31 plasma samples expressed wild-type $K R A S$, mutations were detected in $22 / 31$ patients, and for $2 / 31$ patients, the test did not provide a conclusive result. A total of 24/31 patients expressed wild-type $N R A S, 6 / 31$ had mutations and 1/21 was not informative. For the KRAS mutational status, a moderate concordance (agreement, 85.18\%; Cohen's $\mathrm{k}, 0.513$ ) between the tissue and plasma analysis was observed; for NRAS, a fair agreement (agreement, 83.33\%; Cohen's k, 0.242) was obtained. In conclusion, both tissue and plasma analyses should be performed for the management of patients with mCRC. To better exploit the beads, emulsions,
\end{abstract}

Correspondence to: $\mathrm{Dr}$ Elena Lastraioli, Department of Experimental and Clinical Medicine, University of Florence, Viale G.B. Morgagni 50, I-50134 Florence, Italy

E-mail: elena.lastraioli@unifi.it

Key words: metastatic colorectal cancer, KRAS, NRAS, mass spectrometry, beads, emulsions amplification, magnetics amplification, magnetics (BEAMing) technique in the clinical setting, studies aimed at determining the $R A S$ status to monitor therapy and during follow-up are warranted.

\section{Introduction}

Colorectal cancer $(\mathrm{CRC})$ represents the third most frequent tumor worldwide and the second cause of cancer-related death, with 1.8 million cases and 862,000 deaths in 2018 according to the World Health Organization estimates (1). Despite advances in early diagnosis and treatment, the mortality rate is still high due to the development of distant metastases as synchronous (in $20.00 \%$ of patients) (2) or metachronous ( $40.00 \%$ of patients) disease (3). Patients with metastatic (m)CRC are generally treated with surgery and/or systemic therapy carried out using either standard chemotherapy, biological agents or a combination of the two methods (4). Considering targeted therapy with biological agents, certain patients will respond to therapy, whereas others will not due to their genetic features (5).

A previous study has demonstrated that $\mathrm{mCRC}$ is characterized by a high frequency of mutations in the $R A S$ gene that are the main determinants of the failure of anti-EGFR-based therapy such as cetuximab and panitumumab (6). Therefore, patients with mCRC are routinely screened for $B R A F, K R A S$ and NRAS mutations to select the appropriate patients who are more likely to have a positive response when treated with anti-EGFR (7-9). The most frequent mutations associated with a poor response to EGFR therapy are located in KRAS exon 2 (codons 12 and 13, 40.00\% of patients), although other codons (59 and 61 in exon 3, 117 and 146 in exon 4) may be affected, as well as mutations in NRAS (codons 12, 13, 59, 61, 117 and 146) (10-14). RAS status is currently determined in tissue samples, either from the primary tumor or from metastasis obtained during biopsy or surgery.

Since patients with mCRC patients are characterized by poor health conditions, multiple biopsies should be avoided; however, it has been demonstrated that a single tissue biopsy may not be representative of the whole tumor due to 
intratumoral heterogeneity (15). In addition, tissue biopsy cannot be used in these patients for disease monitoring for the same reason. Based on this, the concept of liquid biopsy has been proposed as a surrogate for a tissue sample (16-22). In previous years technological improvements have enabled the study of circulating tumor cells (CTCs) and circulating tumor DNA (ctDNA) in the peripheral blood samples of patients with advanced cancers $(23,24)$. Previous studies have demonstrated that ctDNA levels are associated with clinicopathological and biological features such as tumor histological type, stage, burden, blood vessel proximity, apoptotic rate and metastatic potential (17,25-28). Among patients with mCRC, it has been demonstrated that a high proportion of patients (86.00-100.00\%) is characterized by detectable ctDNA in plasma, and that $1.90-27.00 \%$ of total ctDNA harbor different mutations (26).

The aims of the present study were as follows: i) To analyze the concordance between KRAS and NRAS mutational status evaluated in the tissue and the plasma from a cohort of patients with $\mathrm{mCRC}$ (synchronous or metachronous); ii) to evaluate the association between KRAS and NRAS mutations in the ctDNA and patient clinicopathological features; and iii) to analyze the mutant allele fraction (MAF) distribution in the plasma samples and identify potential clinical associations.

\section{Materials and methods}

Patients. The study cohort included 31 patients with mCRC enrolled at Medical Oncology Unit, Azienda Ospedaliero-Universitaria Careggi (Florence, Italy) between January 2017 and August 2018 following written informed consent and approval from the Ethical Committee of Azienda Ospedaliero-Universitaria Careggi (approval no. BIO.16.028, 25/10/2016). All patients were previously diagnosed with clinical Tumor-Node-Metastasis stage IV (29) and had measurable disease according to the Response Evaluation Criteria in Solid Tumors version 1.1 (30).

Tissue samples. For all patients, KRAS and NRAS status had been previously determined in tissue biopsies of either primary tumors or metastases by using the Myriapod ${ }^{\circledR}$ Colon Status kit (Diatech Pharmacogenetics Srl), which allows the detection of 216 mutations in oncogenes responsible for colorectal cancerogenesis (KRAS, BRAF, PIK3CA, NRAS) using the genotyping platform MassARRAY ${ }^{\circledR}$ system (Sequenom, Inc.) based on matrix-assisted laser desorption ionization-time of flight (MALDI-TOF) mass spectrometry.

Selection of biological samples and DNA extraction. Hematoxylin-eosin sections from biopsies of neoplastic colorectal tissues were obtained from the archive of the Pathological Anatomy department of Azienda Ospedaliero-Universitaria Careggi and then revised by two experienced pathologists. Only sections containing $\geq 100$ neoplastic cells were selected. Corresponding formalin-fixed paraffin-embedded blocks were obtained and $10-\mu \mathrm{m}$ tissue sections were cut, deparaffinized with solvent, rinsed in alcohol and dried before processing. DNA was extracted from tissue sections a using MagCore Genomic DNAFFPE One-Step kit (RBC Bioscience Corp.) and then analyzed for quality and concentration using a spectrophotometer. If the quality was optimal and the concentration was between $2.5-25.0 \mathrm{ng} / \mathrm{ml}$, the samples were amplified.

DNA Amplification. DNA was amplified by multiplex-PCR using the Master Amp-Mix amplification mixture (Diatech Pharmacogenetics Srl) in order to obtain fragments comprising all polymorphic sites of interest. The reaction mixture contained $1.3 \mu \mathrm{l}$ water, $0.5 \mu \mathrm{l}$ PCR buffer, $0.4 \mu \mathrm{l} \mathrm{MgCl}_{2}, 0.1 \mu \mathrm{l}$ dNTP mix and $0.2 \mu \mathrm{l}$ PCR enzyme. All PCR mixes were placed on a plate and added to a negative control ( $2 \mu \mathrm{l}$ water), a sample ( $2 \mu$ l extracted DNA) and a positive control $(2 \mu$ l human wild-type control DNA provided with the kit). Following spinning the reaction mixture by brief centrifugation at maximum speed, the plate was put in a thermocycler with the following amplification profile: $95^{\circ} \mathrm{C}$ for $2 \mathrm{~min}$; followed by 45 cycles of $95^{\circ} \mathrm{C}$ for $30 \mathrm{sec}, 56^{\circ} \mathrm{C}$ for $30 \mathrm{sec}$ and $72^{\circ} \mathrm{C}$ for $60 \mathrm{sec} ; 72^{\circ} \mathrm{C}$ for $5 \mathrm{~min} ; 4^{\circ} \mathrm{C}$ for $5 \mathrm{~min}$; and hold at $10^{\circ} \mathrm{C}$.

Treatment with shrimp alkaline phosphatase (SAP) and iPLEX extension. Following the amplification, the amplification products were treated with SAP (provided with the kit) to remove nucleotide residues. A SAP cocktail (SAP-Mix) containing $1.53 \mathrm{ml}$ water, $0.17 \mathrm{ml}$ SAP Buffer and $0.30 \mathrm{ml}$ SAP Enzyme was prepared for each sample. The samples were added to the SAP-Mix and placed in a thermocycler with the following conditions: $37^{\circ} \mathrm{C}$ for $40 \mathrm{~min} ; 85^{\circ} \mathrm{C}$ for $5 \mathrm{~min} ; 4^{\circ} \mathrm{C}$ for $5 \mathrm{~min}$; and hold at $10^{\circ} \mathrm{C}$. Subsequently, each sample was extended using a Master Ext-Mix extension mixture. Each mixture comprised $0.56 \mathrm{ml}$ water, $0.20 \mu \mathrm{l}$ Buffer Plus, $0.20 \mathrm{ml}$ Termination mix and $0.04 \mathrm{ml}$ Thermosequenase for each sample reaction. The samples were placed in a thermocycler with the Master Ext-Mix and processed under the following thermocycling conditions: $94^{\circ} \mathrm{C}$ for $30 \mathrm{sec}$; followed by 40 cycles of $94^{\circ}$ for $5 \mathrm{sec}, 5$ cycles of $52^{\circ} \mathrm{C}$ for $5 \mathrm{sec}$ and 5 cycles of $80^{\circ} \mathrm{C}$ for $5 \mathrm{sec}$; $72^{\circ} \mathrm{C}$ for $3 \mathrm{~min} ; 4^{\circ} \mathrm{C}$ for $5 \mathrm{~min}$; and hold at $10^{\circ} \mathrm{C}$.

Spectra acquisition and analysis. Once the extension reaction was completed, the reaction products were dispensed on a SpectroCHIP ${ }^{\circledR}$ II G96 using the Nanodispenser RS-1000 ${ }^{\circledR}$ Instrument. The SpectroCHIP was then placed in the MassARRAY ${ }^{\circledR}$ Analyzer 4 Instrument for spectra acquisition. The generated spectra were analyzed using the MassARRAY ${ }^{\circledR}$ database with iGenetics ${ }^{\circledR}$ Myriapod ${ }^{\circledR}$ software version 5.1 (Diatech Pharmacogenetics Srl).

Blood sample collection. Peripheral blood $(8 \mathrm{ml})$ was collected from each patient enrolled in the study in $\mathrm{K}_{2}$ EDTA BD Vacutainer ${ }^{\circledR}$ collection tubes (BD Biosciences) immediately before starting therapy. The plasma was isolated within $4 \mathrm{~h}$ according to the Sysmex-Inostics protocol for the determination of KRAS and NRAS status with the OncoBEAM ${ }^{\circledR}$ RAS $\mathrm{CRC}$ assay (Sysmex Inostics). The plasma samples were stored at $-80^{\circ} \mathrm{C}$.

ctDNA extraction and purification. ctDNA was extracted from the plasma and purified using a QIAamp ${ }^{\circledR}$ Circulating Nucleic Acid kit and QIAvac24 plus (both from Qiagen $\mathrm{GmbH}$ ) according to the manufacturer's protocol with slight modifications as indicated by Sysmex Inostics. 
BEAMing assay. For the detection of RAS mutations in the ctDNA, OncoBEAM ${ }^{\circledR}$ RAS CRC kit (Sysmex Inostics) was used according to the manufacturer's instructions. The ctDNA samples were amplified with a multiplex PCR performed as follows: $98^{\circ} \mathrm{C}$ for $30 \mathrm{sec}$; followed by 21 cycles of $98^{\circ} \mathrm{C}$ for $15 \mathrm{sec}, 60^{\circ} \mathrm{C}$ for $25 \mathrm{sec}$ and $72^{\circ} \mathrm{C}$ for $25 \mathrm{sec} ; 72^{\circ} \mathrm{C}$ for $35 \mathrm{sec}$; and hold at $4^{\circ} \mathrm{C}$. The multiplex PCR was followed by pooling and dilution with $1 \mathrm{X} \mathrm{pH} \mathrm{8.0} \mathrm{TE} \mathrm{buffer} \mathrm{to} \mathrm{get} \mathrm{the}$ optimal amount of PCR product for each codon. The diluted samples together with specific positive and negative controls [part of the OncoBEAM ${ }^{\circledR}$ RAS CRC kit, (Sysmex Inostics $\mathrm{GmbH}$ ) and carrying specific mutations and no template, respectively] were used for emulsion PCR. Following cycling, magnetic beads bound to the amplicons were retrieved through a breaking phase followed by the hybridization step carried out with specific fluorescent probes for further detection by Cube6i flow cytometer (Sysmex Inostics). The breaking phase was carried out according to the manufacturer's protocol provided with the OncoBEAM ${ }^{\circledR}$ RAS CRC kit using a magnet and two buffers, Breaking Buffer 1 and 2 , provided with the kit. The hybridization step performed as follows: $70^{\circ} \mathrm{C}$ for $30 \mathrm{sec}$, gradual decrease from $70^{\circ} \mathrm{C}$ to $24^{\circ} \mathrm{C}$ with a $3 \%$ ramp rate; $24^{\circ} \mathrm{C}$ for $1 \mathrm{~min}$; and hold at $21^{\circ} \mathrm{C}$. After the completion of the run, the data were exported and analyzed by FCS Express version 5.0 software (Denovo software; Sysmex Inostics).

Statistical analysis. The demographic, clinical and biological characteristics of the patients are presented as frequencies and percentages. Continuous variables are presented as the median (range of variation). To evaluate the associations between $R A S$ mutational status and clinicopathological features, parametric (Fisher's exact) and non-parametric (Kruskal-Wallis) tests were used as appropriate. Data were analyzed using the statistical software Stata 9.1 (StataCorp LP). A two-sided $P$ value $\leq 0.05$ was considered to indicate a statistically significant difference. For categorical variables, the samples were classified as follows: Sex, male vs. female; localization of the primary tumor, right colon vs. left colon vs. rectum; pathological stage at the time of ctDNA analysis, relapse vs. newly diagnosed stage IV tumor; histological type, adenocarcinoma vs. mucinous adenocarcinoma; grading, G2 vs. G3; number of metastatic sites at the time of ctDNA analysis, 1 vs. 2 vs. 3 vs. >3; surgery for primary tumor, yes vs. no. The percentage of agreement was evaluated according to the Cohen's $\kappa$ of concordance and its $95.00 \%$ confidence interval.

\section{Results}

Clinical characteristics. In the present study, a total of 31 patients were enrolled (16 female, 15 male) with a mean age 67 years (range, 46-85 years) and a histologically diagnosed mCRC not treated for the metastatic disease. The primary tumor was mainly localized in the colon (80.64\%) with a similar distribution between the left and right colon. Among the patients, $64.52 \%$ received surgery with curative intent for the primary disease and developed metachronous metastases. The main demographic and clinicopathological features of the cohort are presented in Table I.
Table I. Demographic and clinicopathological characteristics of the study cohort.

\begin{tabular}{|c|c|}
\hline Characteristic & No. of patients ( \\
\hline \multicolumn{2}{|l|}{ Sex } \\
\hline Female & $16(51.61)$ \\
\hline Male & $15(48.39)$ \\
\hline \multicolumn{2}{|l|}{ Localization } \\
\hline Left colon & $12(38.71)$ \\
\hline Right colon & $13(41.94)$ \\
\hline Rectum & $6(19.35)$ \\
\hline \multicolumn{2}{|l|}{$\begin{array}{l}\text { Pathological stage at the } \\
\text { time of ctDNA analysis }\end{array}$} \\
\hline Synchronous & $18(58.06)$ \\
\hline Metachronous & $13(41.94)$ \\
\hline \multicolumn{2}{|l|}{ Histological type } \\
\hline Adenocarcinoma & $24(87.10)$ \\
\hline Mucinous adenocarcinoma & $7(12.90)$ \\
\hline \multicolumn{2}{|l|}{ Grading } \\
\hline $\mathrm{G} 2$ & $19(61.29)$ \\
\hline G3 & $3(9.68)$ \\
\hline Undefined & $9(29.03)$ \\
\hline \multicolumn{2}{|l|}{$\begin{array}{l}\text { Metastatic sites at the time of } \\
\text { ctDNA analysis }\end{array}$} \\
\hline Only liver & $8(25.81)$ \\
\hline Only lung & $1(3.23)$ \\
\hline Peritoneum & $4(12.90)$ \\
\hline Multiple & $18(58.06)$ \\
\hline
\end{tabular}

Number of metastatic sites at the time of ctDNA analysis

$\begin{array}{lr}1 & 13(41.93) \\ 2 & 12(38.71) \\ \geq 3 & 6(19.36)\end{array}$

Surgery for primary tumor No Yes

Tissue used for molecular analysis of $R A S$ mutational status

$\begin{array}{lr}\text { Primary tumor } & 23(74.19) \\ \text { Metastasis } & 8(25.81)\end{array}$

ctDNA, circulating tumor DNA.

RAS mutational status in tissue samples. Molecular determination of $R A S$ status in paraffin-embedded samples was performed using primary tumor samples in $74.19 \%$ of the patients and in metastatic tissues in the remaining $25.81 \%$ of the patients. The analysis was performed by MALDI-TOF mass spectrometry associated to single base extension technology and provided conclusive results for all patients; six samples (19.35\%) expressed the wild-type form of KRAS, and 25 samples $(80.65 \%)$ harbored mutations (Table II). The same analysis was performed for NRAS, showing the presence of 
Table II. KRAS and NRAS analysis of tissue samples.

\begin{tabular}{lc}
\hline$R A S$ status & No. of patients $(\%)$ \\
\hline Wild-type KRAS & $6(19.35)$ \\
Mutated $K R A S$ & $25(80.65)$ \\
Exon 2 codon 12 & $19(76.00)$ \\
G12A & 4 \\
G12C & 3 \\
G12D & 10 \\
G12V & 2 \\
Exon 2 codon 13 & $5(20.00)$ \\
G13D & 4 \\
G13V & 1 \\
Exon 3 codon 59 & $0(0.00)$ \\
Exon 3 codon 61 & $0(0.00)$ \\
Exon 4 codon 117 & $0(0.00)$ \\
Exon 4 codon 146 & $1(4.00)$ \\
A146P & 1 \\
Wild-type NRAS & $30(96.77)$ \\
Mutated NRAS & $1(3.23)$ \\
Exon 2 codon 12 & $1(100.00)$ \\
G12D & 1 \\
Exon 2 codon 13 & $0(0.00)$ \\
Exon 3 codon 59 & $0(0.00)$ \\
Exon 3 codon 61 & $0(0.00)$ \\
Exon 4 codon 117 & $0(0.00)$ \\
Exon 4 codon 146 & $0(0.00)$ \\
Undefined & $0(0.00)$ \\
\hline
\end{tabular}

a mutation in only one patient $(96.77 \%$ wild-type and $3.23 \%$ mutated) (Table II).

RAS mutational status in plasma samples. RAS mutational status was analyzed using BEAMing technology. Of the 31 samples analyzed, wild-type $K R A S$ was identified in seven patients, whereas mutations were detected in 22 patients (17 in codon 12, four in codon 13, one in codon 146); for two patients, an informative result could not be obtained. Regarding NRAS analysis, the wild-type form of the gene was observed in 24 patients, two patients harbored a mutation in codon 12 , four harbored a mutation in codon 61 and the data for one patient was not informative (Table III). Fig. 1 demonstrates representative plots obtained using the BEAMing assay (left plots, 'universal signal' vs. 'mutant signal'; right plots, 'wild-type signal' vs. 'mutant signal'). In Fig. 1A, the results of a no template control are presented, and no signal is present in the right plot. By contrast, in the two plots in Fig. 1B representing the positive control, an intense signal in the gate corresponding to mutant beads (mtP3) can be observed. In Fig. 1C and D, two representative samples classified as wild-type and mutated, respectively, are demonstrated: In the former, almost no signal is present in mtP3 gate, whereas in the latter, the presence of the mutation is marked by the black dots in the mrP3 quadrant (see arrow).
Table III. KRAS and NRAS analysis of plasma samples.

\begin{tabular}{lc}
\hline$R A S$ status & No. of patients $(\%)$ \\
\hline Wild-type KRAS & $7(22.58)$ \\
Mutated KRAS & $22(77.42)$ \\
Exon 2 codon 12 & $17(77.27)$ \\
Exon 2 codon 13 & $4(18.18)$ \\
Exon 3 codon 59 & $0(0.00)$ \\
Exon 3 codon 61 & $0(0.00)$ \\
Exon 4 codon 117 & $0(0.00)$ \\
Exon 4 codon 146 & $1(4.55)$ \\
Not informative & 2 \\
Total & 31 \\
Wild-type NRAS & $24(77.42)$ \\
Mutated NRAS & $6(22.58)$ \\
Exon 2 codon 12 & $2(33.33)$ \\
Exon 2 codon 13 & $0(0.00)$ \\
Exon 3 codon 59 & $0(0.00)$ \\
Exon 3 codon 61 & $4(66.67)$ \\
Exon 4 codon 117 & $0(0.00)$ \\
Exon 4 codon 146 & $0(0.00)$ \\
Not informative & 1 \\
Total & 31 \\
\end{tabular}

The technique used to analyze these plasma samples from patients with mCRC did not provide the result of the test as an absolute number of $R A S$ mutated alleles, but as the mutant allele fraction (MAF), which is the ratio (expressed as a percentage) of mutated and wild-type $R A S$ alleles (Table IV). Analysis of the mutated samples (mutated beads $\geq 40$ ) revealed large variability among patients, and the mean number of mutant beads was $6,047.909 \pm 1.594(\mathrm{n}=22)$ for $K R A S$ and $281 \pm 0.103(\mathrm{n}=5)$ for NRAS (Table IV, last row).

For the majority of the patients, a single mutation either in KRAS or NRAS was detected (28/31), whereas three patients presented with mutations in both genes. Notably, in two of these three patients (patients COL002 and COL018), a KRAS mutation was also identified in the tissue sample, whereas NRAS mutations were detected only in the plasma. In both cases, the allele frequency of KRAS (MAF, 21.226 and 7.645) was higher compared with that of NRAS (MAF, 0.031 and $0.344)$; this result was not unexpected since the BEAMing technique exhibited higher sensitivity compared with that of MALDI-TOF mass spectrometry, and thus it is possible that a number of the mutations were not detected in the tissue samples if their frequency was low, as observed in these patients.

The concordance between the results obtained in the tissue and plasma samples was subsequently evaluated (Table V). Analysis of the data using Cohen's $\kappa$ revealed a moderate concordance between tissue and plasma analysis of KRAS mutational status (agreement, 85.18\%; Cohen's $\kappa, 0.513$ ); for NRAS mutational status a fair agreement was found (agreement, 83.33\%; Cohen's $\kappa, 0.242$ )

In order to evaluate the association between $R A S$ mutational status and patient clinicopathological features, the 
A

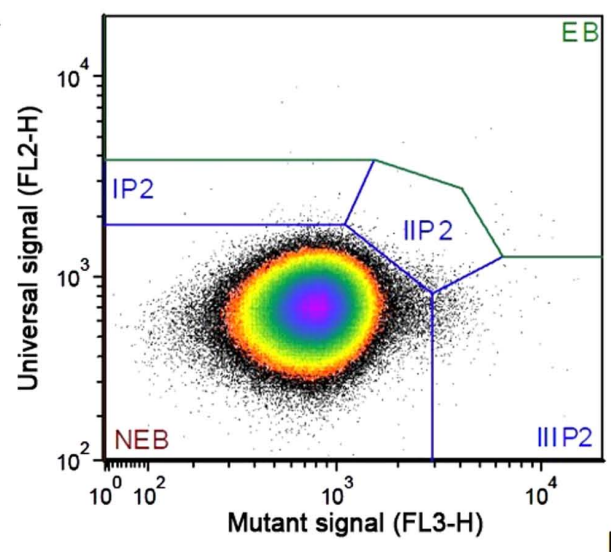

B

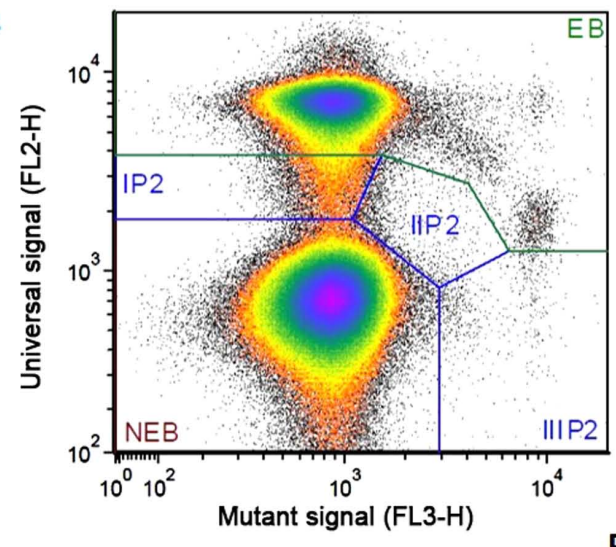

PC

C

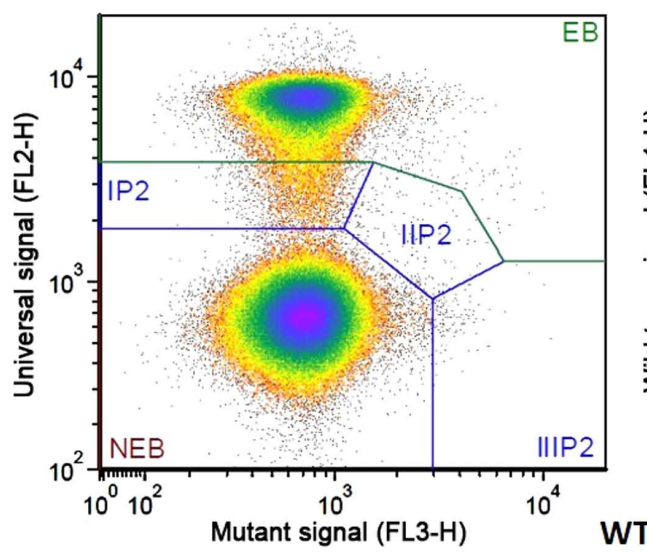

D

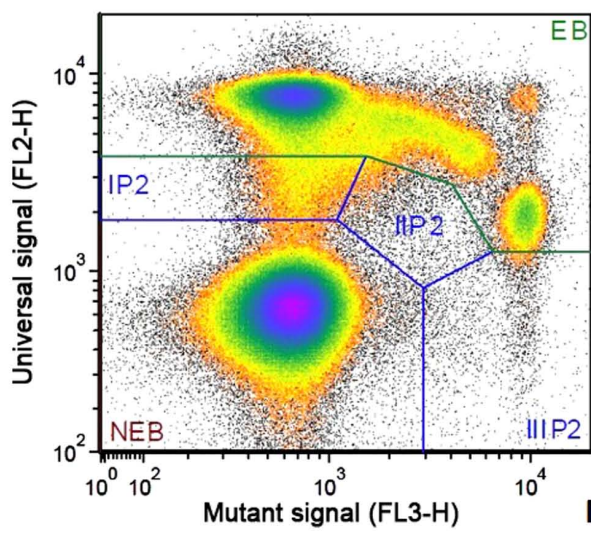

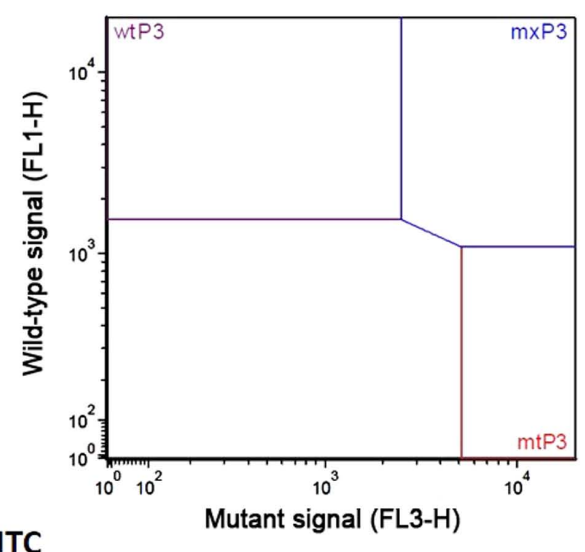

NTC
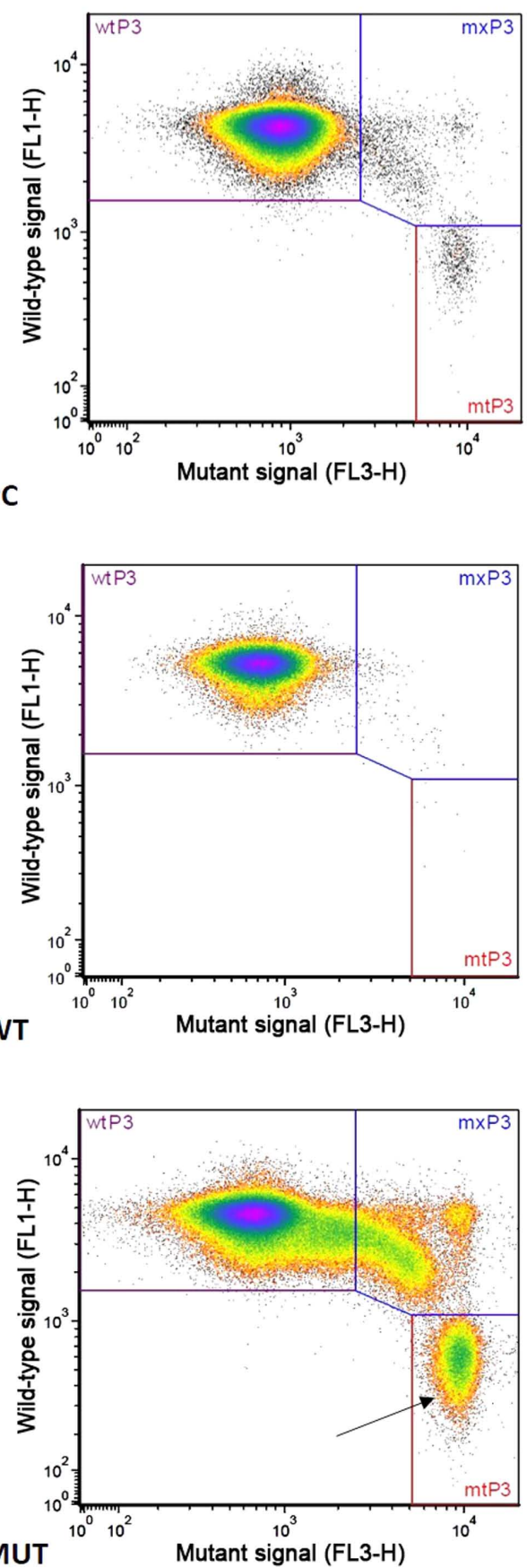

Figure 1. Representative plots obtained by BEAMing assay. In the left plot of each panel 'universal signal' vs. 'mutant signal' is reported, whereas in the right plot, 'wild-type signal' vs. 'mutant signal' is presented. (A) Negative control; (B) PC; mutant beads, 844; mutant fraction, 0.46\%; (C) WT; mutant beads, 14; mutant fraction, 0.02\%; (D) MUT; mutant beads, 14,746; mutant fraction, 7.645 (see arrow). EB, extended beads; NEB, non-extended beads; wt, wild-type; mx, mutant and wild-type; mt, mutant; NTC, no template control; PC, positive control; WT, wild-type sample; MUT, mutant sample. 
Table IV. OncoBEAM ${ }^{\circledR} R A S$ colorectal cancer test results.

\begin{tabular}{|c|c|c|c|c|c|c|}
\hline \multirow[b]{2}{*}{ Patient ID } & \multicolumn{3}{|c|}{$K R A S$} & \multicolumn{3}{|c|}{$N R A S$} \\
\hline & Mutant beads (n) & MAF & Test result & Mutant beads (n) & MAF & Test result \\
\hline COL001 & 8 & 0.013 & Wild-type & 13 & 0.041 & Wild-type \\
\hline COL002 & 97,951 & 21.226 & Mutation detected & 65 & 0.031 & Mutation detected \\
\hline COL003 & 6,862 & 5.610 & Mutation detected & 6 & 0.011 & Wild-type \\
\hline COL004 & 36,785 & 13.006 & Mutation detected & 8 & 0.009 & Wild-type \\
\hline COL005 & 12,879 & 6.759 & Mutation detected & 22 & 0.020 & Wild-type \\
\hline COL006 & 1,516 & 0.998 & Mutation detected & 17 & 0.058 & Wild-type \\
\hline COL007 & 32,095 & 5.262 & Mutation detected & 4 & 0.002 & Wild-type \\
\hline COL008 & 6 & 0.005 & Wild-type & 49 & 0.053 & Mutation detected \\
\hline COL009 & 43,649 & 9.861 & Mutation detected & 7 & 0.002 & Wild-type \\
\hline COL010 & 7 & 0.009 & Wild-type & 2 & 0.005 & Wild-type \\
\hline COL011 & 691 & 0.653 & Mutation detected & 0 & 0.000 & Wild-type \\
\hline COL012 & 51,794 & 11.216 & Mutation detected & 4 & 0.001 & Wild-type \\
\hline COL013 & 137 & 0.144 & Mutation detected & 6 & 0.015 & Wild-type \\
\hline COL014 & 70 & 0.068 & Mutation detected & 9 & 0.022 & Wild-type \\
\hline COL015 & 29 & 0.012 & Wild-type & 10 & 0.007 & Wild-type \\
\hline COL016 & 292 & 0.045 & Mutation detected & 7 & 0.002 & Wild-type \\
\hline COL017 & 29,038 & 28.149 & Mutation detected & 2 & 0.002 & Wild-type \\
\hline COL018 & 14,746 & 7.645 & Mutation detected & 164 & 0.344 & Mutation detected \\
\hline COL019 & 9,023 & 5.455 & Mutation detected & 3 & 0.017 & Wild-type \\
\hline COL020 & 45 & 0.056 & Mutation detected & NI & NI & NI \\
\hline OB3 & 61 & 0.053 & Mutation detected & 22 & 0.025 & Wild-type \\
\hline OB4 & 7,861 & 11.211 & Mutation detected & 1 & 0.002 & Wild-type \\
\hline OB5 & NI & NI & NI & 1 & 0.003 & Wild-type \\
\hline OB7 & 2 & 0.005 & Wild-type & 0 & 0.000 & Wild-type \\
\hline OB8 & 1,178 & 0.918 & Mutation detected & 6 & 0.005 & Wild-type \\
\hline OB9 & 10,639 & 4.693 & Mutation detected & 5 & 0.004 & Wild-type \\
\hline OB10 & 42 & 0.017 & Mutation detected & 429 & 0.469 & Mutation detected \\
\hline OB11 & 24 & 0.028 & Wild-type & 246 & 0.516 & Mutation detected \\
\hline OB12 & 15 & 0.013 & Wild-type & 5 & 0.009 & Wild-type \\
\hline OB14 & NI & NI & NI & 9 & 0.023 & Wild-type \\
\hline OB15 & 0 & 0.000 & Wild-type & 7 & 0.012 & Wild-type \\
\hline Mean \pm SEM & $6,047.909 \pm 1.594$ & & & $281 \pm 0.103$ & & \\
\hline
\end{tabular}

MAF, mutant allele fraction; NI, not informative; SEM, standard error of the mean; detected mutations are indicated in bold.

samples were divided into two groups: Wild-type and mutated (either $K$ - or NRAS). No significant associations were identified between the two groups (Table VI).

\section{Discussion}

Emerging evidence has demonstrated the importance of liquid biopsy as a surrogate of standard tissue biopsies for diagnostic purposes as well as for monitoring patients with mCRC (16-21). In particular, in mCRC patients, multiple biopsies should be avoided due to their poor general health conditions.

In 2016, a meta-analysis reported that ctDNA may represent an indicator for poor prognosis, including both recurrence-free survival and overall survival (OS), in patients with stage I-IV CRC (28). A study performed by Spindler et al (31) demonstrated that an increase in ctDNA reduced the progression-free survival (PFS) and OS (defined as the months elapsed from the first diagnosis and the progression of the disease or death of the patient, respectively) time with a hazard ratio of 1.4 (95\% CI, 1.1-1.7; $\mathrm{P}=0.03)$ and $1.6(95 \% \mathrm{CI}, 1.3-2.0 ; \mathrm{P}<0.0001)$, respectively. In addition, their study revealed that the evaluation of $K R A S$ mutations in the plasma provided additional information on the patient outcome (31). A recent study performed a parallel analysis of ctDNA and circulating tumor cells (CTCs) and demonstrated that the former represented an improved tool for the management of patients with CRC since CTCs were not detected in all samples in contrast to ctDNA, and a low volume of blood was sufficient for the molecular analysis (32). 
Table V. Concordance between tissue and plasma analysis of $R A S$ mutational status.

\begin{tabular}{|c|c|c|c|c|c|c|}
\hline \multirow[b]{2}{*}{ Patient ID } & \multicolumn{3}{|c|}{$K R A S$} & \multicolumn{3}{|c|}{ NRAS } \\
\hline & Tissue & Plasma & Concordance & Tissue & Plasma & Concordance \\
\hline COL001 & G12D & wt & no & wt & wt & yes \\
\hline COL002 & $\mathrm{G} 12 \mathrm{C}$ & $\mathrm{Cd} 12$ & yes & wt & $\mathrm{Cd} 12$ & no \\
\hline COL003 & G12A & $\mathrm{Cd} 12$ & yes & wt & wt & yes \\
\hline COL004 & G12D & Cd12 & yes & wt & wt & yes \\
\hline COL005 & G13D & Cd13 & yes & wt & wt & yes \\
\hline COL006 & G12C & $\mathrm{Cd} 12$ & yes & wt & wt & yes \\
\hline COL007 & G12D & $\mathrm{Cd} 12$ & yes & wt & wt & yes \\
\hline COL008 & wt & wt & yes & G12D & CD12 & yes \\
\hline COL009 & G13D & Cd13 & yes & wt & wt & yes \\
\hline COL010 & G13D & Cd13 & yes & wt & wt & yes \\
\hline COL011 & G12D & Cd12 & yes & wt & wt & yes \\
\hline COL012 & G12A & $\mathrm{Cd} 12$ & yes & wt & wt & yes \\
\hline COL013 & G13D & Cd13 & yes & wt & wt & yes \\
\hline COL014 & G12A & $\mathrm{Cd} 12$ & yes & wt & wt & yes \\
\hline COL015 & G13V & wt & no & wt & wt & yes \\
\hline COL016 & G12D & $\mathrm{Cd} 12$ & yes & wt & wt & yes \\
\hline COL017 & G146P & Cd146 & yes & wt & wt & yes \\
\hline COL018 & G12D & $\mathrm{Cd} 12$ & yes & wt & CD61 & no \\
\hline COL019 & $\mathrm{G} 12 \mathrm{C}$ & $\mathrm{Cd} 12$ & yes & wt & wt & yes \\
\hline COL020 & G12D & $\mathrm{Cd} 12$ & yes & wt & NI & NA \\
\hline OB3 & G12D & $\mathrm{Cd} 12$ & yes & wt & wt & yes \\
\hline OB4 & G12D & $\mathrm{Cd} 12$ & yes & wt & wt & yes \\
\hline OB5 & wt & $\mathrm{NI}$ & NA & wt & wt & yes \\
\hline OB7 & G12D & wt & no & wt & wt & yes \\
\hline OB8 & G12V & $\mathrm{Cd} 12$ & yes & wt & wt & yes \\
\hline OB9 & G12A & $\mathrm{Cd} 12$ & yes & wt & wt & yes \\
\hline OB10 & wt & $\mathrm{Cd} 12$ & no & wt & CD61 & no \\
\hline OB11 & wt & wt & yes & wt & CD61 & no \\
\hline OB12 & wt & wt & yes & wt & wt & yes \\
\hline OB14 & wt & NI & NA & wt & CD61 & no \\
\hline OB15 & G12V & wt & no & wt & wt & yes \\
\hline
\end{tabular}

NI, not informative; NA, not applicable (since one of the evaluations is missing); wt, wild-type. Detected mutations are indicated in bold.

Overall, the frequency of $K$ - and $N$-RAS mutations in the present study was higher compared with the one expected to be observed in the general population, although notably, for a part of the cohort, one of the inclusion criteria was the presence of KRAS mutations.

In the cohort of patients analyzed in this study, coexistence of $K$ - and $N$-RAS mutations was observed in $3 / 31$ patients $(9.70 \%)$. For two patients, MAF values were higher for $K R A S$ compared with those for $N R A S$, whereas an opposite trend was observed in the third patient. Although $K$ - and $N-R A S$ mutations are generally mutually exclusive, the high sensitivity of BEAMing may allow the identification of subclonal mutations that may have been missed with other techniques. However, since these mutations are present at in a small proportion of patients their biological and clinical relevance requires further investigation. It may have been be interesting to apply the BEAMing technology to the tissue samples to evaluate whether such subclonal mutations were present in the tumor tissues as well as in the plasma, but it was not possible to identify them due to the lower sensitivity of the standard techniques applied in the analyses of tissue samples.

The results of the present study identified a concordance between BEAMing and MALDI-TOF, as previously reported in other studies $(33,34)$. Overall, for the KRAS mutational status, five samples were not in accordance. The possible causes of such discordance were subsequently explored. In four patients, a mutation was detected in the tissue, but not in the plasma; this observation may be explained by the elimination of sensitive clones by the treatment if the two analyses were performed at different times (as in patients OB7 and OB15); on the other hand, the discrepancy may also have occurred due to the low tumor burden if the two analyses were performed at 
Table VI. Associations between $R A S$ mutational status and clinicopathological features.

\begin{tabular}{|c|c|c|c|c|}
\hline \multirow[b]{2}{*}{ Clinical feature } & \multirow[b]{2}{*}{$\mathrm{n}$} & \multicolumn{2}{|c|}{$R A S$ mutational status, $\mathrm{n}(\%)$} & \multirow[b]{2}{*}{ P-value } \\
\hline & & Wild-type & Mutated & \\
\hline Sex & & & & $0.355^{\mathrm{a}}$ \\
\hline Male & 15 & $3(20.00)$ & $12(80.00)$ & \\
\hline Female & 16 & $3(18.75)$ & $13(81.25)$ & \\
\hline Age, years & & & & $0.221^{\mathrm{b}}$ \\
\hline Mean, 67 (range, 46-85) & 31 & $6(19.35)$ & $25(80.65)$ & \\
\hline Localization & & & & $0.333^{\mathrm{a}}$ \\
\hline Right colon & 13 & $1(7.69)$ & $12(92.31)$ & \\
\hline Left colon & 12 & $3(25.00)$ & $9(75.00)$ & \\
\hline Rectum & 6 & $2(33.33)$ & $4(66.67)$ & \\
\hline Pathological stage at the time of ctDNA analysis & & & & $>0.999^{\mathrm{a}}$ \\
\hline Synchronous & 18 & $3(16.67)$ & $15(83.33)$ & \\
\hline Metachronous & 13 & $3(23.08)$ & $10(76.92)$ & \\
\hline Histological type & & & & $0.287^{\mathrm{a}}$ \\
\hline Adenocarcinoma & 24 & $3(12.50)$ & $21(87.50)$ & \\
\hline Mucinous adenocarcinoma & 7 & $3(42.86)$ & $4(57.14)$ & \\
\hline Grading & & & & $0.422^{\mathrm{a}}$ \\
\hline G1 & 0 & $0(0.00)$ & $0(0.00)$ & \\
\hline G2 & 19 & $3(15.79)$ & $16(84.21)$ & \\
\hline G3 & 3 & $1(33.33)$ & $2(66.67)$ & \\
\hline Undefined & 9 & $2(22.22)$ & 7 (77.78) & \\
\hline Number of metastatic sites at the time of ctDNA analysis & & & & $0.413^{\mathrm{a}}$ \\
\hline 1 & 13 & $1(7.69)$ & $12(92.31)$ & \\
\hline 2 & 12 & $5(41.67)$ & $7(58.33)$ & \\
\hline$\geq 3$ & 6 & $0(0.00)$ & $6(100.00)$ & \\
\hline Surgery for primary tumor & & & & $>0.999^{\mathrm{a}}$ \\
\hline No & 11 & $3(27.27)$ & $8(72.73)$ & \\
\hline Yes & 20 & $3(15.00)$ & $17(85.00)$ & \\
\hline
\end{tabular}

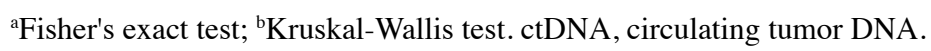

similar times (as in patients COL001 and COL015). COL001 and COL015, harboring KRAS mutations in the tissue, but not in the plasma, had mucinous tumors and underwent surgical resection with curative intent. In addition, the analysis of radiographic images captured on a date close to the blood collection demonstrated that the two patients exhibited a low tumor burden (localization of the disease limited to the peritoneum in one patient and relatively small metastases in the liver in the other). These results were in accordance with those obtained in a large multicenter prospective cohort, which demonstrated that surgery of the primary tumor, absence of liver metastases and peritoneal localization were significantly associated with inconclusive results in the plasma (35).

In one patient (OB10), a mutation was detected in the plasma, but not in the tissue. Since the BEAMing assay is more sensitive compared with MALDI-TOF mass spectrometry, the mutation may have been missed due to the low MAF (0.017). Another explanation may be that mutations may have developed a long time after diagnosis and evaluation of $R A S$ mutational status in tissue samples, and if tissue analysis was performed using tissues obtained during a biopsy, the mutation may have been missed due to the heterogeneity and the low tumor cell fraction in the specimen. This patient had a long and satisfactory response ( 2 years) to therapy that has been recently published as a case report (36) and may represent an example of rechallenge failure due to molecular determinants. In particular, since the patient exhibited a complete response to Cetuximab, after two years, the treatment was repeated using the same drug, but the disease rapidly progressed; the analysis of plasma in this case may have helped determine a different schedule of treatment.

In addition, for $N R A S$, five samples were not in accordance; a mutation was detected in the plasma, whereas the tissues was classified as harboring wild-type $N R A S$. This discrepancy may be explained as aforementioned.

A potential limitation of the present study was the absence of validation of the data obtained through BEAMing with a different technique. In the present study, it was not possible 
to obtain such confirmation, since the amount DNA available from each patient was not enough to perform other experiments with various methodologies, and no additional blood collection was performed due to the general conditions of the patients to avoid enhancing their discomfort. Such evaluation represents a future perspective and will be performed in a further study. However, in patients with low MAF (such as patient OB10) with a value close to the cut-off, BEAMing analysis was performed twice to verify the result since additional methods could not be performed.

A recent multicenter clinical study performed in Japan provided clinical validation of the OncoBEAM ${ }^{\circledR}$ RAS CRC assay (37), paving the road to the incorporation of BEAMing into clinical practice. The results of the aforementioned study, although it was performed on a larger cohort compared to the one used in the present study, were in concert with the findings of the present study since they obtained an overall concordance between tissue and plasma analyses equal to $86.4 \%$.

Overall, the results of the present study identified a certain degree of agreement between the two techniques. Based on these preliminary data, it is suggested that both analyses should be routinely performed to provide clinicians an additional tool for the management of patients with mCRC. To confirm these results, validation studies on larger cohorts are warranted, as well as studies aimed at determining the $R A S$ status to monitor therapy and during follow-up.

\section{Acknowledgements}

The authors would like to thank Dr Caterina Fattorini (Section of Pathological Anatomy, Department of Health Sciences, University of Florence, Azienda Ospedaliero-Universitaria Careggi) for integrating the methods concerning tissue analysis. Part of these data were presented at EACR-ESMO Joint Conference on Liquid Biopsies, held in Bergamo (Italy) on May 15th-17th 2019.

\section{Funding}

No funding was received.

\section{Availability of data and materials}

The datasets used and/or analyzed during the current study are available from the corresponding author on reasonable request.

\section{Authors' contributions}

EL performed the experiments, analyzed the data and wrote the manuscript. LA enrolled and followed up the patients, retrieved clinical data and wrote the manuscript. BF enrolled and followed up the patients, contributed to analysis of the data and writing the manuscript. LDC collected the samples and participated in data analysis. ADC retrieved clinical data and participated in data analysis. DL enrolled and followed up the patients and contributed to interpreting and analyzing data. MA participated in performing the experiments. AA participated in the study design and revised the manuscript. FC performed molecular analysis on tissue specimens. LM performed histological diagnoses. FDC designed and supervised the study and revised the manuscript. All authors read and approved the final manuscript.

\section{Ethics approval and consent to participate}

The present study was approved by the Ethical Committee of Azienda Ospedaliero-Universitaria Careggi (approval no. BIO.16.028, 25/10/2016). All patients were enrolled after providing written informed consent.

\section{Patient consent for publication}

Not applicable.

\section{Competing interests}

The authors declare that they have no competing interests.

\section{References}

1. International Agency for Research on Cancer: Colorectal cancer. Source: Globocan 2018. The Global Cancer Observatory, 2019.

2. Cook AD, Single R and McCahill LE: Surgical resection of primary tumors in patients who present with stage IV colorectal cancer: An analysis of surveillance, epidemiology, and end results data, 1988 to 2000. Ann Surg Oncol 12: 637-645, 2005.

3. van Gestel YR, de Hingh IH, van Herk-Sukel MP, van Erning FN, Beerepoot LV, Wijsman JH, Slooter GD, Rutten HJ, Creemers GJ and Lemmens VE: Patterns of metachronous metastases after curative treatment of colorectal cancer. Cancer Epidemiol 38: 448-454, 2014.

4. Van Cutsem E, Cervantes A, Nordlinger B, Arnold D; ESMO Guidelines Working Group: Metastatic colorectal cancer: ESMO Clinical Practice Guidelines for diagnosis, treatment and follow-up. Ann Oncol 25 (Suppl 3): iii1-9, 2014.

5. Xie YH, Chen YX and Fang JY: Comprehensive review of targeted therapy for colorectal cancer. Signal Transduct Target Ther 5: 22, 2020

6. Qiu LX, Mao C, Zhang J, Zhu XD, Liao RY, Xue K, Li J and Chen Q: Predictive and prognostic value of KRAS mutations in metastatic colorectal cancer patients treated with cetuximab: a meta-analysis of 22 studies. Eur J Cancer 46: 2781-2787, 2010.

7. Benson AB III, Venook AP, Bekaii-Saab T, Chan E, Chen YJ, Cooper HS, Engstrom PF, Enzinger PC, Fenton MJ, Fuchs CS, et al: Colon cancer, version 3. 2014. J Natl Compr Canc Netw 12: 1028-1059, 2014.

8. Van Cutsem E, Cervantes A, Adam R, Sobrero A, Van Krieken JH, Aderka D, Aranda Aguilar E, Bardelli A, Benson A, Bodoky G, et al: ESMO consensus guidelines for the management of patients with metastatic colorectal cancer. Ann Oncol 27: 1386-1422, 2016.

9. Allegra CJ, Rumble RB and Schilsky RL: Extended RAS gene mutation testing in metastatic colorectal carcinoma to predict response to anti epidermal growth factor receptor monoclonal antibody therapy: American society of clinical oncology provisional clinical opinion update 2015 summary. J Oncol Pract 12: 180-181, 2016.

10. Douillard JY, Oliner KS, Siena S, Tabernero J, Burkes R, Barugel M, Humblet Y, Bodoky G, Cunningham D, Jassem J, et al: Panitumumab-FOLFOX4 treatment and RAS mutations in colorectal cancer. N Engl J Med 369: 1023-1034, 2013.

11. Heinemann V, von Weikersthal LF, Decker T, Kiani A, Vehling-Kaiser U, Al-Batran SE, Heintges T, Lerchenmüller C, Kahl C, Seipelt G, et al: FOLFIRI plus cetuximab versus FOLFIRI plus bevacizumab as first-line treatment for patients with metastatic colorectal cancer (FIRE-3): A randomised, open-label, phase 3 trial. Lancet Oncol 15: 1065-1075, 2014.

12. Bokemeyer C, Köhne CH, Ciardiello F, Lenz HJ, Heinemann V, Klinkhardt U, Beier F, Duecker K, van Krieken JH and Tejpar S: FOLFOX4 plus cetuximab treatment and RAS mutations in colorectal cancer. Eur J Cancer 51: 1243-1252, 2015. 
13. Peeters M, Oliner KS, Price TJ, Cervantes A, Sobrero AF, Ducreux M, Hotko Y, André T, Chan E, Lordick F, et al: Analysis of KRAS/NRAS mutations in a phase III study of panitumumab with FOLFIRI compared with FOLFIRI alone as second-line treatment for metastatic colorectal cancer. Clin Cancer Res 21 : $5469-5479,2015$.

14. Van Cutsem E, Lenz HJ, Köhne CH, Heinemann V, Tejpar S, Melezínek I, Beier F, Stroh C, Rougier P, van Krieken JH and Ciardiello F: Fluorouracil, leucovorin, and irinotecan plus cetuximab treatment and RAS mutations in colorectal cancer. J Clin Oncol 33: 692-700, 2015.

15. Jamal-Hanjani M, Quezada SA, Larkin J and Swanton C: Translational implications of tumor heterogeneity. Clin Cancer Res 21: 1258-1266, 2015.

16. Gormally E, Caboux E, Vineis P and Hainaut P: Circulating free DNA in plasma or serum as biomarker of carcinogenesis: Practical aspects and biological significance. Mutat Res 635: 105-117, 2007.

17. Diehl F, Schmidt K, Durkee KH, Moore KJ, Goodman SN, Shuber AP, Kinzler KW and Vogelstein B: Analysis of mutations in DNA isolated from plasma and stool of colorectal cancer patients. Gastroenterology 135: 489-498, 2008.

18. Hodgson DR, Wellings R, Orr MC McCormack R, Malone M, Board RE and Cantarini MV: Circulating tumour-derived predictive biomarkers in oncology. Drug Discov Today 15: 98-101, 2010.

19. Jung K, Fleischhacker M and Rabien A: Cell-free DNA in the blood as a solid tumor biomarker-a critical appraisal of the literature. Clin Chim Acta 411: 1611-1624, 2010.

20. Schwarzenbach H, Stoehlmacher J, Pantel K and Goekkurt E: Detection and monitoring of cell-free DNA in blood of patients with colorectal cancer. Ann N Y Acad Sci 1137: 190-196, 2008.

21. De Mattos-Arruda L, Olmos D and Tabernero J: Prognostic and predictive roles for circulating biomarkers in gastrointestinal cancer. Future Oncol 7: 1385-1397, 2011.

22. Pantel $\mathrm{K}$ and Alix-Panabières $\mathrm{C}$ : Real-time liquid biopsy in cancer patients: Fact or fiction? Cancer Res 73: 6384-6388, 2013.

23. Haber DA and Velculescu VE: Blood-based analyses of cancer: Circulating tumor cells and circulating tumor DNA. Cancer Discov 4: 650-661, 2014.

24. Ma M, Zhu H, Zhang C, Sun X, Gao X and Chen G: 'Liquid biopsy'-ctDNA detection with great potential and challenges. Ann Transl Med 3: 235, 2015.

25. Chen CC, Er TK, Liu YY, Hwang JK, Barrio MJ, Rodrigo M, Garcia-Toro E and Herreros-Villanueva M: Computational analysis of KRAS mutations: Implications for different effects on the KRAS p.G12D and p.G13D mutations. PLoS One 8: e55793, 2013.

26. Bettegowda C, Sausen M, Leary RJ, Kinde I, Wang Y, Agrawal N, Bartlett BR, Wang H, Luber B, Alani RM, et al: Detection of circulating tumor DNA in early- and late-stage human malignancies. Sci Transl Med 6: 224ra24, 2014.

27. El Messaoudi S, Mouliere F, Du Manoir S, Bascoul-Mollevi C, Gillet B, Nouaille M, Fiess C,Crapez E, Bibeau F, Theillet C, et al: Circulating DNA as a strong multimarker prognostic tool for metastatic colorectal cancer patient management care. Clin Cancer Res 22: 3067-3077, 2016.
28. Basnet S, Zhang ZY, Liao WQ, Li SH, Li PS and Ge HY: The prognostic value of circulating cell-free DNA in colorectal cancer: A meta-analysis. J Cancer 7: 1105-1113, 2016.

29. TNM Classification of Malignant Tumours. Sobin LH, Gospodarowicz MK and Wittekind Ch (eds). 7th edition. Wiley-Blackwell, 2011.

30. Eisenhauer EA, Therasse P, Bogaerts J, Schwartz LH, Sargent D, Ford R, Dancey J, Arbuck S, Gwyther S, Mooney M, et al: New response evaluation criteria in solid tumours: Revised RECIST guideline (version 1.1). Eur J Cancer 45: 228-247, 2009.

31. Spindler KL, Appelt AL, Pallisgaard N, Andersen RF, Brandslund I and Jakobsen A: Cell-free DNA in healthy individuals, noncancerous disease and strong prognostic value in colorectal cancer. Int J Cancer 135: 2984-2991, 2014.

32. Germano G, Mauri G, Siravegna G, Dive C, Pierce J, Di Nicolantonio F, D'Incalci M, Bardelli A, Siena S and Sartore-Bianchi A: Parallel evaluation of circulating tumor DNA and circulating tumor cells in metastatic colorectal cancer. Clin Colorectal Cancer 17: 80-83, 2018.

33. Schmiegel W, Scott RJ, Dooley S, Lewis W, Meldrum CJ, Pockney P, Draganic B, Smith S, Hewitt C, Philimore H, et al: Blood-based detection of RAS mutations to guide anti-EGFR therapy in colorectal cancer patients: Concordance of results from circulating tumor DNA and tissue-based RAS testing. Mol Oncol 11: 208-219, 2017.

34. García-Foncillas J, Tabernero J, Élez E, Aranda E, Benavides M, Camps C, Jantus-Lewintre E, López R, Muinelo-Romay L, Montagut C, et al: Prospective multicenter real-world RAS mutation comparison between OncoBEAM-based liquid biopsy and tissue analysis in metastatic colorectal cancer. Br J Cancer 119: 1464-1470, 2018.

35. Bachet JB, Bouché O, Taieb J, Dubreuil O, Garcia ML, Meurisse A, Normand C, Gornet JM, Artru P, Louafi S, et al: RAS mutation analysis in circulating tumor DNA from patients with metastatic colorectal cancer: The AGEO RASANC prospective multicenter study. Ann Oncol 29: 1211-1219, 2018.

36. Lastraioli E, Lavacchi D, Palmieri VE, Castiglione F, Messerini L, Di Costanzo F and Antonuzzo L: Evaluation of RAS mutational status through BEAMing assay to monitor disease progression of metastatic colorectal cancer: A case report. Anticancer Drugs 31: 979-982, 2020.

37. Bando H, Kagawa Y, Kato T, Akagi K, Denda T, Nishina T, Komatsu Y, Oki E, Kudo T, Kumamoto H, et al: A multicentre, prospective study of plasma circulating tumour DNA test for detecting RAS mutation in patients with metastatic colorectal cancer. Br J Cancer 120: 982-986, 2019.

This work is licensed under a Creative Commons Attribution-NonCommercial-NoDerivatives 4.0 International (CC BY-NC-ND 4.0) License. 